\title{
Temperature Dependence of Soft Mode Frequency, Dielectric Constant and Loss Tangent in Deuterated KDP Crystal
}

\author{
ANUBHUTI MAMGAIN and TRILOK CHANDRA UPADHYAY* \\ Physics Department, H N B Garhwal University, (A Central University), \\ Srinagar (Garhwal), Uttarakhand-246174, India \\ anubhuti.mamgain01@gmail.com
}

Received 24 November 2015 / Accepted 10 December 2015

\begin{abstract}
By fitting model values for physical quantities for deuterated KDP crystal in theoretically derived expressions for soft mode frequency, dielectric constant and loss tangent in our earlier paper temperature dependence of these quantities have been calculated and compared with experimental data of Kaminow which show a good agreement.
\end{abstract}

Keywords: Ferroelectrics, Green's functions, Dielectric constant, Loss tangent, Phase transition

\section{Introduction}

Potassium dihydrogen phosphate $\mathrm{KH}_{2} \mathrm{PO}_{4}$ crystal undergoes ferroelectric transition at $123 \mathrm{~K}$. The large isotope shift of phase transition temperature $\left(\mathrm{T}_{\mathrm{c}} 229 \mathrm{~K}\right.$ for $\left.\mathrm{KD}_{2} \mathrm{PO}_{4}\right)$ suggests that the proton dynamics plays an essential role in phase transition mechanism. KDP $\left(\mathrm{KH}_{2} \mathrm{PO}_{4}\right)$ crystal is model order-disorder ferroelectric crystal. Its isomorphs constitute a large group of ferroelectric crystals. It is ferroelectric below $123 \mathrm{~K}$ (orthorhombic) and paraelectric above $123 \mathrm{~K}$ (tetragonal). The lattice parameters are $\mathrm{a}=7.899 \AA, \mathrm{b}=6.325 \AA, \mathrm{c}=4.890 \AA$ and $\beta=108.29^{0}$. The $\mathrm{PO}_{4}$ groups are connected by O-H---O bonds, which forms double-well potential. Below $\mathrm{T}_{\mathrm{c}}$ protons are ordered in one of two minima of potential.

Extensive experimental studies on KDP and its deuterated from (DKDP) have been carriedout by many experimentalists. Leroudier et al. ${ }^{1}$ have done crystal growth study of KDP and DKDP crystals. Li et al. ${ }^{2}$ have also made crystal growth and optical studies of KDP and DKDP crystals. Strukov et al. ${ }^{3}$ have made hysteresis loop and specific heat studies on KDP and DKDP crystals. Ettomi et $a l^{4}$ have made thermal analysis studies on KDP and DKDP crystals. Chai et al..$^{5}$ have made Raman scattering studies on KDP and DKDP crystals. Abalmassov et al. ${ }^{6}$ have made dielectric susceptibility and Raman scattering studies on DKDP crystals. Pereira et al. ${ }^{7}$ have done Raman scattering studies on DKDP crystals. 
Theoretical studies on KDP were initiated by Ganguli et al. ${ }^{8}$ who have considered pseudo spin model. They have used Green's function method and obtained soft mode frequency, dielectric susceptibility and transition temperature etc.

Earlier researchers ${ }^{8}$ have not considered third-order phonon anharmonic interaction. They have decoupled the correlations at an early stage. So that they could not produce better and convincing results. In our earlier paper, we have considered third and fourth order phonon anharmonic terms.

In the present study we shall fit model values of physical quantities in the expressions obtained in our earlier paper ${ }^{9}$ for KDP crystal. Temperature dependences of soft mode frequency, dielectric constant and loss tangent will be calculated for $\mathrm{KD}_{2} \mathrm{PO}_{4}$ crystal. Theoretical results will be compared with experimentally reported results of Kaminow $^{10}$.

\section{Calculation and Results}

In our earlier paper a pseudo-spin - lattice coupled mode model ${ }^{9}$ along with thirsd and fourth-order phonon anharmonic interactions terms ${ }^{11}$ has been considered for KDP type crystals. Using this Hamiltonian, the double- time thermal Green's function ${ }^{12}$ was evaluated which was obtained as;

$$
G(\omega)=\pi^{-1} \Omega\left\langle S_{i}^{x}\right\rangle \delta_{i j}\left[\left(\omega^{2}-\hat{\Omega}^{2}\right)+2 i \Omega \Gamma(\omega)\right]^{-1},
$$

where

$$
\begin{gathered}
\hat{\Omega}^{2}=\tilde{\Omega}^{2}+\Delta(\omega), \\
\widetilde{\Omega}^{2}=a^{2}+b^{2}-b c, \\
a=J_{0}\left\langle S^{z}\right\rangle, \\
b=2 \Omega ; \\
c=J_{0}\left\langle S^{x}\right\rangle
\end{gathered}
$$

In Eqs. 1 and 2, $\Gamma(\omega)$ and $\Delta(\omega)$ are width and shift respectively which are given in our earlier paper, $\hat{\Omega}$ is modified soft mode frequency given as;

$$
\hat{\Omega}_{-}^{2}=\frac{1}{2}\left\{\left(\widetilde{\widetilde{\omega}}_{\mathrm{k}}^{2}+\widetilde{\widetilde{\Omega}}^{2}\right) \pm\left[\left(\widetilde{\widetilde{\omega}}_{\mathrm{k}}^{2}-\widetilde{\Omega}^{2}\right)^{2}+16 \mathrm{~V}_{\mathrm{ik}}\left\langle\mathrm{S}_{1}^{\mathrm{x}}\right\rangle \Omega\right]^{1 / 2}\right\}
$$

The dielectric constant was obtained ${ }^{9}$ as;

$$
\epsilon=\left(-8 \pi N \mu^{2}\right)\left\langle S^{x}\right\rangle\left(\omega^{2}-\hat{\Omega}^{2}\right)\left[\left(\omega^{2}-\hat{\Omega}^{2}\right)^{2}+4 \Omega^{2} \Gamma^{2}\right]^{-1} .
$$

The dielectric tangent loss was given by;

$$
\tan \delta=\frac{2 \Omega \Gamma(\omega)}{\hat{\Omega}^{2}}
$$

The terms appearing in Eqs(1)-(9) have been defined in our earlier paper'. By using model values of physical quantities appearing in expressions (7), (8) and (9) (Table 1) their temperature dependences are calculated for DKDP crystal. The values of $\left\langle S_{1}^{z}\right\rangle,\left\langle S_{1}^{x}\right\rangle$ are calculated using their expressions in our earlier paper ${ }^{9}$. Then values of $\hat{\Omega}, \varepsilon$ and $\tan \delta$ are 
calculated for DKDP crystal and shown in Figures 1-3. The calculated values of $\hat{\Omega}, \varepsilon$ and $\tan \delta$ for DKDP crystal have been compared with experimental values of Kaminow ${ }^{10}$.

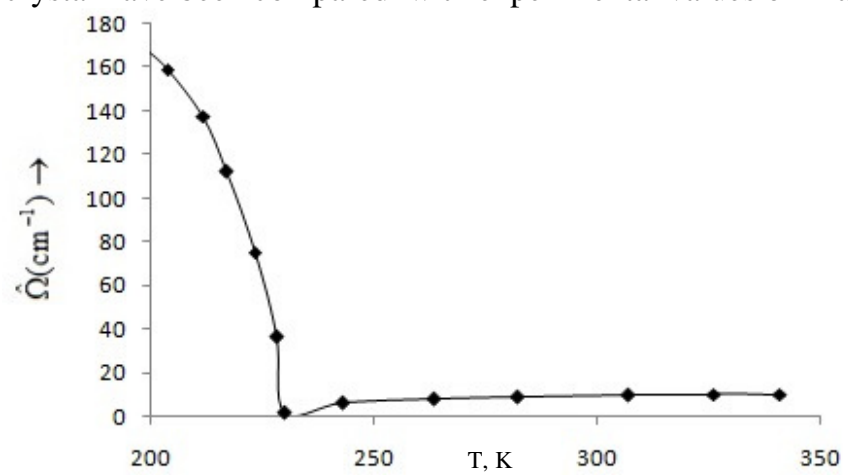

Figure 1. Calculated temperature dependence of soft mode frequency $(\hat{\Omega})$ in deuterated KDP crystal correlated with exp-, $\operatorname{Exp}^{10}$

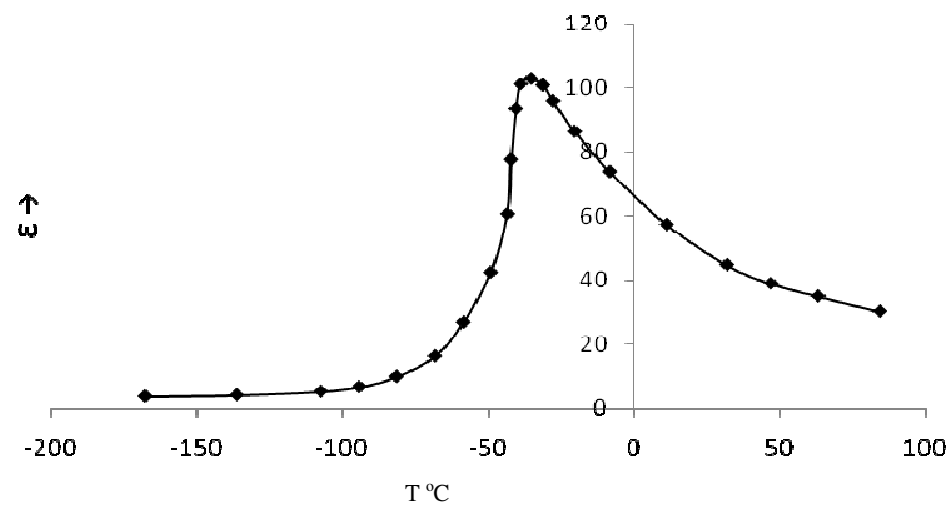

Figure 2. Calculated temperature dependence of dielectric constant $(\varepsilon)$ in deuterated KDP crystal-, $\operatorname{Exp}^{10}$

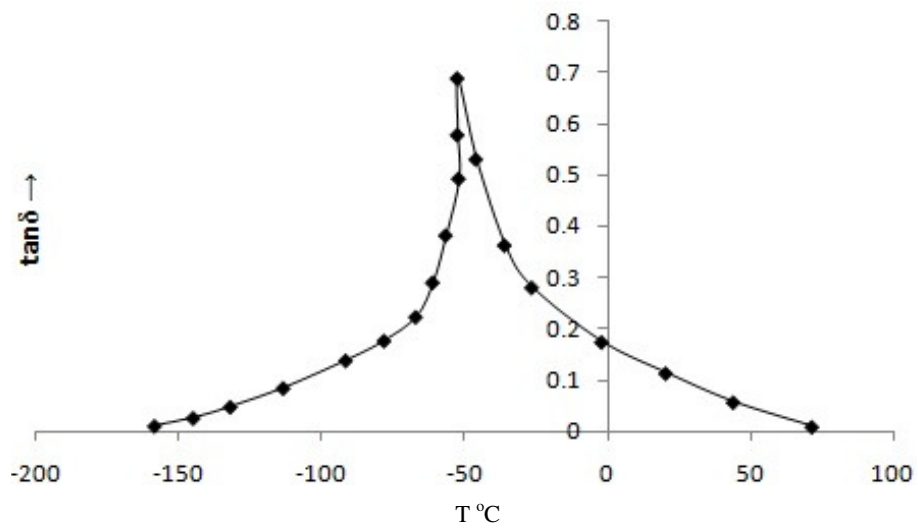

Figure 3. Calculated temperature dependence of loss tangent $(\tan \delta)$ in deuterated KDP crystal-, $\operatorname{Exp}^{10}$ 
Table 1. Model values of physical quantities for DKDP crystal (ref. 15)

\begin{tabular}{ccccccccc}
\hline$\Omega, \mathrm{cm}^{-1}$ & $\mathrm{~J}, \mathrm{~cm}^{-1}$ & $\begin{array}{c}\mathrm{J}^{*}, \\
\mathrm{~cm}^{-1}\end{array}$ & $\begin{array}{c}\text { Vik, } \\
\mathrm{cm}^{1}\end{array}$ & $\mathrm{~T}_{\mathrm{c}} \mathrm{k}$ & $\omega_{\mathrm{k}}$ & $\mathrm{C}$ & $\mu$, esu & $\mathrm{A}_{\mathrm{k}}(\mathrm{erg} / \mathrm{K})$ \\
\hline 0.486 & 472 & 626 & 0.299 & 229 & 153 & 373 & $1.3 \times 10^{-18}$ & $9.7 \times 10^{17}$ \\
\hline
\end{tabular}

\section{Discussion}

In the present work, by fitting model values of physical quantities in the expressions obtained in our earlier paper for DKDP crystal, thermal variations of soft mode frequency, dielectric constant and loss tangent have been calculated. Theoretical results have been compared with experimentally reported results for deuterated KDP crystal. Our model for KDP type crystals, i.e. pseudo spin-lattice coupled mode model along with third- and fourthorder phonon anharmonic terms explains consistently and simply the salient features of phase transition and dielectric properties of KDP and DKDP crystals. The main aim of the present work is to explain isotope effect in DKDP. On deuteration, the transition temperature shifts from 123 to $229 \mathrm{~K}$ and both dielectric constant and loss tangent versus temperature curves shift to quite new values. Our expression for transition temperature $T_{c}$ with values for DKDP crystal explains fairly isotope effect on $T_{c}$. Our expressions given in Eqs (8-10) explain temperature dependence of ferroelectric frequency, dielectric constant and loss tangent for DKDP. The change in tunneling frequency is mainly responsible for isotope effects in DKDP crystal. Hence, with the expressions obtained for KDP crystal with and different values of physical quantities for DKDP crystal, one can explain ferroelectric, dielectric and isotope effects in deuterated KDP crystal.

\section{Conclusion}

Present study reveals that the modified model i.e. pseudo spin-lattice coupled mode model with addition of third- and fourth-order phonon anharmonic interactions terms explain quantitatively well the ferroelectric and dielectric behaviours of pure as well as deuterated KDP crystal. Theoretical results agree with experimental results, which show the applicability of the present modified model for both KDP and DKDP crystals.

\section{Acknowledgements}

Authors are grateful to Eminent Physicist Prof B.S. Semwal (Former HOD) for his suggestions and to Prof R.P Gairola, Prof U C Naithani, Prof S C Bhatt (HOD) and Dr Manish Uniyal for their encouragements.

\section{References}

1. Leroudier J, Zaccaro J, Ildefonso M, Veesler S, Baruchel J, Ibanez A, Cryst Growth Des., 2011, 11(6), 2592-2598; DOI:10.1021/cg200342w

2. $\quad$ Li G, Xue L, Su G, Li Z, Zhuang X and He Y, Cryst Res Techn., 2005, 40(9), 867870; DOI:10.1002/crat.200410447

3. Strukov B, Shnaidshtein I and Grabovsky S, Cond Matt Phys., 2007, 10, 111-118.

4. Ettoumi H, Gao Y, Toumi M and Mihiri T, Ionics, 2013, 19(7), 1067-1075; DOI:10.1007/s11581-013-0926-X

5. Chai X, Xu X, Li F, Feng B, Zhu Q, Wang S, Zhang L, Zhou H, Proceed, SPIE, XX Int'l Symp. On High Power Laser Systems \& Appl. 2014 (Feb 3, 2015), 925541; DOI:10.1117/12.2065295

6. Abalmassov V A, Pugachev A M and Surovtsev N V, Physics Solid State, 2011, 53(7), 1371-1377; DOI:10.1134/S106378341107002X 
7. Pereira D P, deoliveria P C, Remedios C M R, Moreira S G C, de Sousa F F, Filho O M, Freire P T C and Melo F E A, Sol Stat Commun., 2012, 152(12), 1023-1026; DOI:10.1016/j.ssc.2012.03.026

8. Ganguli S, Nath D and Chaudhuri B K, Phy Rev B, 1980, 21(7), 2937; DOI:10.1103/PhysRevB.21.2937

9. Upadhyay T C and Semwal B S, Indian J Pure Appl Phys., 2002, 40, 615.

10. Kaminow I P, Phys Rev., 1965, 138A, 1539-1543.

11. Semwal B S and Sharma P K, (Progr Theor Phys(Japan), 1974, 51(3), 639-655; DOI:10.1143/PTP.51.639

12. Zubarev D N, Sov Phys Usp., 1960, 3(3), 320. 